\section{Water-soluble Polysaccharides from the Leaves of Tussilago farfara L. ELLEN HAALAND}

\section{Department of Chemistry, Agricultural College, Vollebekk, Norway}

Dlant mucilages extracted with water Prom seeds have been examined by several authors and reviewed by Jones and Smith.' They usually contain galac. turonic acid, galactose, and pentoses, and in some cases further information of their composition has been obtained by the methylation procedure and other standard methods of polysaccharide chemistry.

Plant mucilages from leaves are, however, not so well examined. The most important species of traditional pharmacy containing mucilage in its leaves is Tussi. lago farfara L. (coltsfoot), and the only information of the composition of the mucilage found in literature is the state. ment that hydrolysis of the mucilage liberates galactose and pentoses.?

The crude polysaccharide extracted with hot water from coltsfoot leaves contained a considerable amount of silicates (sulfated ash $75 \%$ ) which could be removed by dialysis. Complete hydrolysis of the crude polysaccharide then yielded D-galacturonic acid, D-gelactose, D-glucose, L-arabinose, D-xylose, D-ribose, Lrhamnose, and traces of three different $O$-methyl-sugars.

The crude polysaccharide was divided in five acid fractions by chromatography on a DEAE-cellulose column. Fractions I to IV were eluted with phosphate buffer, and fraction $\mathrm{V}$ by sodium hydroxide. The results are shown in Fig. 1 .

The polysaccharides I to $\mathrm{V}$ appeared to be homogeneous by high voltage electrophoresis in pyridine acetate, borate, and germanate buffers. Results are presented in Table 1. The main fraction $V$ moved as a rather elongated spot, but no conclusive sign of heterogeneity was observed. The qualitative and quantitative composition of the five polysaccharide fractions are given in Table 1 .

It is seen from Table 1 that the polysaccharide fractions contain galacturonic acid, and that the difference between them is a question of the percentage of uronic acid and of the quantitative distribution of the neutral monosaccharide units.

The main fraction is considered to be a pectin because of its high content of galacturonic acid and because hydrolysis by pectinase liberates mainly free galacturonic acid. It also forms a jelly after dialysis.

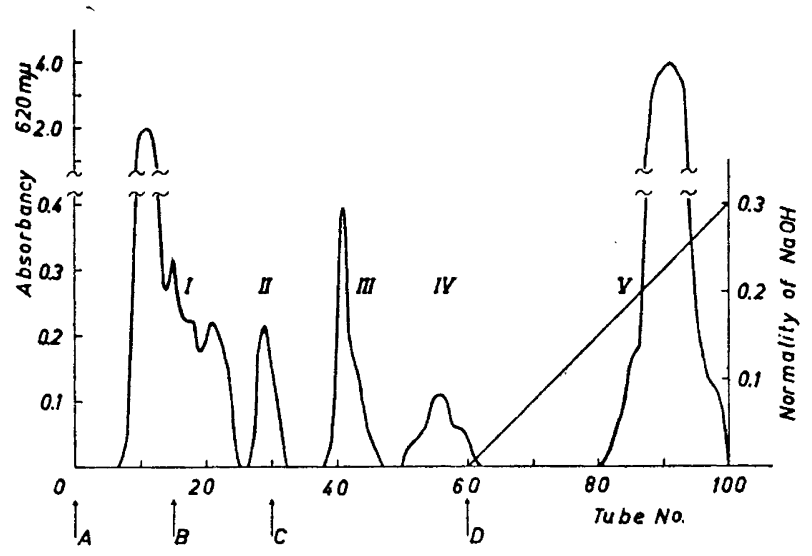

Fig. 1. Fractionation of water-soluble polysaccharide from $T$. farfara L. on DEAE-cellulose. Phosphate form; Eluents: A $0.025 \mathrm{M} ; \mathrm{B} 0.05 \mathrm{M}$; C $0.1 \mathrm{M}$; phosphate buffer $\mathrm{pH}=6$; D gradient $\mathrm{NaOH}$. Tube volume $10 \mathrm{ml}$. The polysaccharides were detected with anthrone reagent. 
Table 1. Electrophoretic mobility and composition of the polysaccharide fractions obtained by chromatography on DEAE-cellulose.

\begin{tabular}{llllllll}
\hline & I & II & III & IV & V \\
\hline
\end{tabular}

Electrophoretic mobility:

$\begin{array}{rlccccc} & \mathrm{M}_{\mathrm{GalA}}{ }^{a} & 0 & 0 & 0.44 & 0.70 & 1.1 \\ & \mathrm{M}_{\mathrm{Glc}}{ }^{b} & 0.59 & 0.56 & 0.59 & 0.53 & 0.93 \\ \text { Yield }(\%) & \mathrm{M}_{\mathrm{Glc}}{ }^{c} & 1.76 & 1.65 & - & - & - \\ {[\alpha]_{\mathrm{D}}^{25}} & & 20 & 5 & 5 & 5 & 65 \\ & & -50 & -10 & +55 & +75 & +160\end{array}$

Monosaccharide content (\%):

D-Galacturonic acid
D-Galactose
D-Glucose
L-Arabinose
D-Xylose
D-Ribose
L-Rhamnose
O-CH - $_{3}$-Sugars

\begin{tabular}{rrrrr}
2 & 2 & 18 & 35 & 67 \\
25 & 13 & 38 & 20 & 11 \\
35 & 66 & 6 & 18 & 5 \\
19 & 13 & 37 & 20 & 8 \\
11 & 6 & $\sim 1$ & & $\sim 1$ \\
$\sim 1$ & & & & 2 \\
6 & & & 7 & 4 \\
$\sim 1$ & & & & $\sim 2$ \\
\hline
\end{tabular}

\footnotetext{
a $\mathbf{M}_{\mathrm{GalA}}$ indicates electrophoretic mobility as compared with galacturonic acid, using a $0.1 \mathrm{M}$ pyridine acetate buffer of $\mathrm{pH}$ 6.5. Dextran was used as stationary marker.

${ }^{b} \mathbf{M}_{\mathrm{Glc}}$ indicates electrophoretic mobility as compared with glucose, using a $0.1 \mathrm{M}$ borate buffer of $\mathrm{pH}$ 10.0. Tetra-O-methyl-D-glucopyranose was used as stationary marker.

$c \mathrm{M}_{\mathrm{Glc}}$ indicates electrophoretic mobility as compared with glucose using a $0.05 \mathrm{M}$ germanate buffer of $\mathrm{pH}$ 10.7. Stationary marker as above $(b)$.

All electrophoretic experiments were performed on glass fibre paper, $25-30 \mathrm{~V} / \mathrm{cm}$. The uronic acid content was determined by the carbazol method. The neutral sugars liberated by hydrol. ysis $\left(2 \mathrm{~N} \mathrm{H}_{2} \mathrm{SO}_{4}, 100^{\circ}, 18 \mathrm{~h}\right.$ ) were determined by quantitative paper chromatography by means of aniline phthalate according to Wilson.
}

It is not surprising that a traditional plant mucilage extracted from leaves appears to contain typical pectic substances. Recent investigations of pectic substances from the leaves of Medicago sativa L." and Plantago major L." gave results which in many respects are similar to those given in the present paper. Research concerning the main fraction (V) is in progress.

Experimental. Paper chromatography was carried out on Whatman No. 1 and 3 MM papers with the following solvent systems (v/v): (A) butanol-acetic acid-water (4:1:5); (B) butanol-pyridine-water $(5: 3: 2)$; (C) ethylacetate-acetic acid-formic acid-water (18:3:1:4); (D) butanol-ethanol-water $(4: 1: 5)$.

Localisation of spots. The reducing sugars were localised with $p$-anisidine hydrochloride (3\% in moist butanol) and aniline phthalate. ${ }^{\circ}$ Polysaccharides on glass fibre paper were detected with $p$-anisidine hydrochloride (1 g $p$-anisidine hydrochloride and $2 \mathrm{ml}$ conc. $\mathrm{H}_{2} \mathrm{SO}_{4}$ in $100 \mathrm{ml}$ moist butanol). Pectins were detected with toluidine blue.?

Extraction of the crude polysaccharide. A commercial sample of coltsfoot leaves (Folium Farfarae, Norsk Medicinaldepot, Oslo) was used. The dried leaves (200 g) were mixed with hot water $(41)$ and kept at $95^{\circ}$ for $1 \mathrm{~h}$. After cooling, the extract was dialysed against tap water (5 days) and concentrated under reduced pressure to about $500 \mathrm{ml}$. Tissue fragments were removed by centrifugation. The crude polysaccharide was precipitated by adding the double volume of ethanol (containing ca. $0.1 \mathrm{~N} \mathrm{HCl}$ ). To purify the polysaccharide it was dissolved in water, centrifugated to remove insoluble materials, and reprecipitated with ethanol as above. $\mathrm{N}$-content $0.4 \%$; sulfated ash $3 \%$; uronic anhydride content by the carbazole method ${ }^{8}$ $50 \%$; degree of esterification $30 \%$, determined

Acta Chem. Scand. 23 (1969) No. 7 
by treatment with excess of $0.1 \mathrm{~N} \mathrm{NaOH}$ and back-titration by $0.1 \mathrm{~N} \mathrm{HCl}$. Hydrolysis of the crude polysaccharide mixture $\left(2 \mathrm{~N} \mathrm{H}_{2} \mathrm{SO}_{4}\right.$, $18 \mathrm{~h}, 100^{\circ}$ ) gave the monosaccharides of Table 1; identified by chromatography in (A), (B), (C), and by measuring $[\alpha]_{D}$ after separation of thick paper.

Degradation with pectinase. Crude polysaccharide was hydrolysed ( $1 \mathrm{~N}_{2} \mathrm{SO}_{4}, 6 \mathrm{~h}$, $100^{\circ}$ ), neutralised with $\mathrm{BaCO}_{3}$, and separated on De-Acedite (formate form) in a neutral and an acid fraction. The latter was incubated for $18 \mathrm{~h}$ at $37^{\circ}$ with pectinase (pure, Sigma).

The enzyme was removed by heating a few minutes at $100^{\circ}$ and filtered through Millipore Membrane filter. Galacturonic acid and small amounts of galactose and arabinose were liberated. Incubation of crude polysaccharide with pectinase under the same conditions as above gave galacturonic acid, galactose, glucose, and arabinose as main components.

Fractionation of the crude polysaccharide was carried out on DEAE cellulose (Whatman DE 11). The polysaccharide $(0.1-0.2 \mathrm{~g})$ was dissolved in water and poured in a column $(2 \times 30 \mathrm{~cm})$ in phosphate form. ${ }^{2}$ The column was eluted as indicated in Fig. 1. The composition of the various fractions is given in Table 1.

1. Jones, J. K. N. and Smith, F. Advan. Carbohydrate Chem. 4 (1949) 264.

2. Steinegger, E. and Hänsel, R. Lehrbuch der allgemeinen Pharmakognosie, Heidelberg 1963.

3. Aspinall, G. O. and Molloy, J. A. J. Chem. Soc. 19682994.

4. Gorin, A. Chem. Abstr. 64 (1966) 8277 d and $11552 \mathrm{~d}$.

5. Lindberg, B. and Swan, B. Acta Chem. Scand. 14 (1960) 1043.

6. Wilson, C. M. Anal. Chem. 31 (1959) 1199.

7. Zweig, G. and Whitaker, J. R., (Ed.), Paper Chromatography and Electrophoresis, Academic, New York and London 1967, Vol. I, p. 252.

8. McComb, E. A. and McCready, R. Anal. Chem. 24 (1952) 1630.

9. Neukom, H., Deuel, H., Heri, W. J. and Kuendig, W. Helv. Chim. Acta 43 (1960) 64.

Received August 12, 1969.

\section{Glucosinolates in Some Erysimum Species}

\section{ROLF GMELIN * and ANDERS KJAER}

Department of Organic Chemistry, Technical

University of Denmark, Lyngby, Denmark

Tn 1957, we reported the presence of 3 carbomethoxypropylglucosinolate $* *$ (I)<smiles>COC(=O)CCCC(=NOS(=O)(=O)O)Sc1ccccc1</smiles>

(I)

in seeds of the cruciferous species Erysimum rupestre DC., $E$. ochroleucum DC., and $E$. pumilum DC. 1 The seed materials employed were propagated in the Botanic Garden of the University of Copenhagen from small seed specimens donated and labelled by a German university botanic garden. Unfortunately, the seed-producing plants were not subjected to botanical control at the time of the cultivation.

In connection with other studies, the three seed samples were sown again in 1966 , and the resulting plants were now kindly investigated botanically by Professor C. Favarger, Institut de Botanique, Université de Neuchatel, who established the three originally studied "species" as identical and different from authentic specimens of $E$. rupestre DC., $E$. ochroleucum DC, and E. pumilum DC. According to Professor Favarger's diagnosis, the original studies were carried out on Erysimum odoratum Ehrh. which should therefore be regarded

* On leave of absence from Freie Universität Berlin.

** The trivial name "glucoerypestrin" was then proposed for this thioglucoside. Subsequent introduction, however, of a semisystematic "glucosinolate"-nomenclature has rendered the original and ambiguous nomenclature superfluous and undesirable (cf. Ref. 2). 